\title{
Arachnoid cyst with spontaneous chronic subdural hematoma: Case report
}

\author{
H. Mozhdehipanah ${ }^{1}, \underline{\text { M. Sayadnasiri }}{ }^{2}$
}

\author{
${ }^{1}$ Department of Neurology, Qazvin University of Medical Sciences, Qazvin, Iran \\ ${ }^{2}$ Department of Clinical Sciences, University of Social Welfare and Rehabilitation Sciences, Tehran, Iran \\ Corresponding Address: Mohammad Sayadnasiri, University of Social Welfare and Rehabilitation Sciences, Razi \\ Hospital, Tehran, Iran \\ Tel: +98-21-33401604; Email: nasiri115@yahoo.com \\ Received: 11 Jul 2018; Accepted: 4 Sep 2018
}

\section{Abstract}

Arachnoid cysts are developmental cerebral disorders that are mostly asymptomatic and diagnosed accidentally on routine brain imaging. Sometimes, these cysts can lead to serious complications such as intracystic and subdural hemorrhage. These hematomas often occur after minor head trauma but in some cases, hemorrhagic complication can occur without obvious predisposing insult. Our reported case is a 19 years old man admitted with acute neurological signs and diagnosed as subdural hematoma and treated without any history of recent head trauma. The only risk factor causing bleeding was arachnoid cyst.

Keywords: Arachnoid cyst, Subdural hematoma, Head trauma

Citation: Mozhdehipanah H, Sayadnasiri M. Arachnoid cyst with spontaneous chronic subdural hematoma: Case report. J Qazvin Univ Med Sci 2018; 22(4): 100-106. 


\title{
خونريزى زير سخت شامهاى مزمن در زمينه كيست آراكنوييد مغزى: كَزارش يك بيمار
}

\author{
دكتر حسين مزدهى يناه'، دكتر محمد صياد نصيرى`
}

كروه مغز و اعصاب دانشكاه علوم يزشكى قزوين، قزوين، ايران

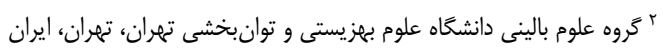

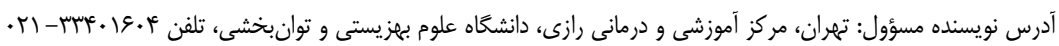
تاريخ دريافت: • •

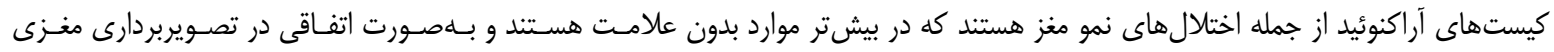

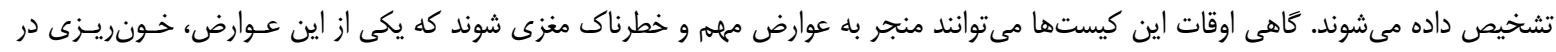

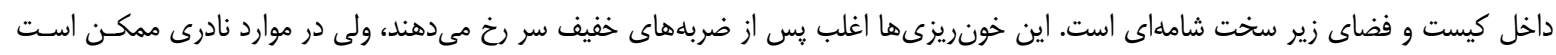

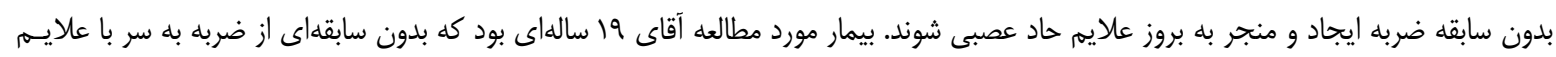

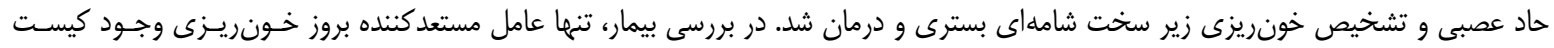
آراكنوئيد بود.

كليدوازهها: كيست آراكنوئيد، خونريزى زير سخت شامهاى، ضربه به سر

كانونى عصبى همراه شود.(ז) از جمله عوارض نـادرى كـهـ

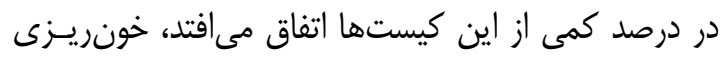

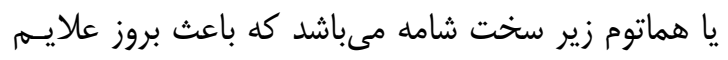

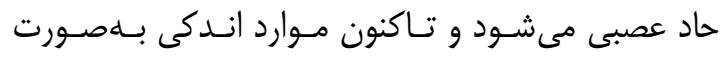

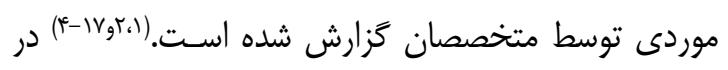
بيشتر اين موارد، خون ريزى متعاقب ضربه بــه سـر بـروز

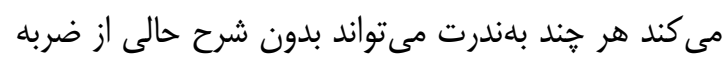

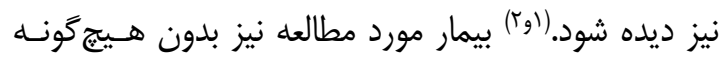

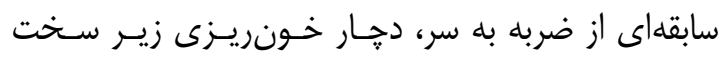
شامهاى گرديد و تحت درمان قرار گرفت.

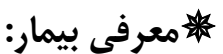

بيمار آقاى 19 سالهاى بود كه با شكايت سـردردهاى دورهاى از جند سال قبل، در سال هوسا به درمانگًاه مغز و اعصاب بيمارستان بوعلى قزوين مراجعه كرد. سـردردهاى

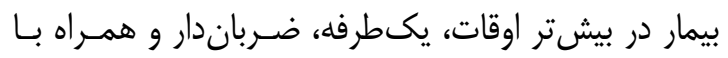

(2) مقدمه:

كيستهاى آراكنوئيد مغـزى تجمعـى از مـايع مغـزى معده نخاعى هستند كه توسط سلولهـاى آراكنوئيسد و كـلازن محصور شدهاند. اين كيستها در بيشتـر مــوارد ناشـى از

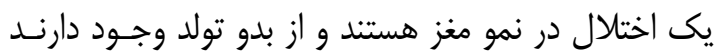

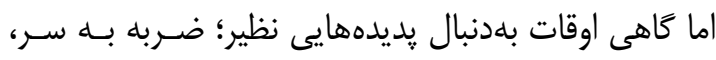
عفونـتهــاى مغـزى و فراينـدهاى نئويلاسـتيك ايجــاد

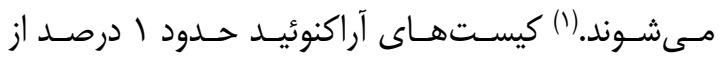

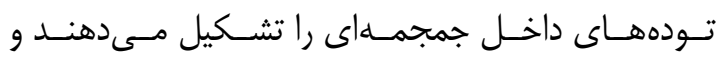
شايعترين محل تشكيل آنها شـكاف سـيلوين در حفـره

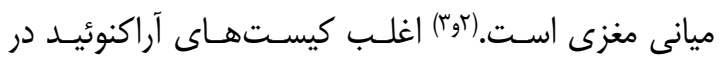
سرتاسر عمر بدون علامت باقى مىمانند و ممكـن اسـت

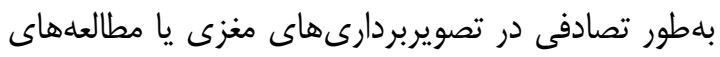
يس از مرگ كشف شوند.(") در موارد علامتدار تظـاهرات بيمارى عمدتاً بلهـورت سـردرد ناشـى از افـزايش فشـار

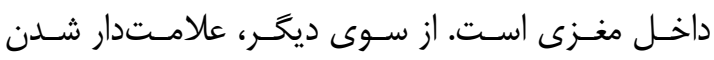

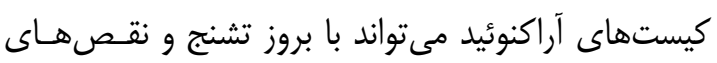


مستعدكنندهاى نظير؛ ضربه به سر، كيستهـاى آراكنوئيـد

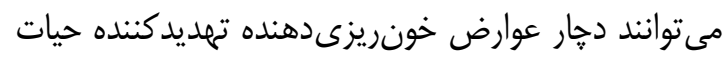

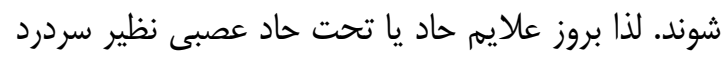

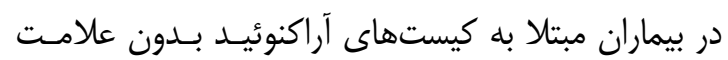

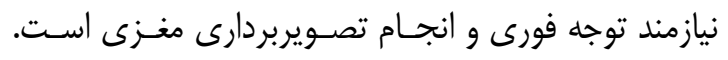

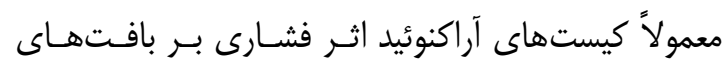

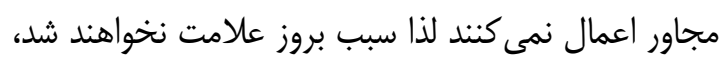

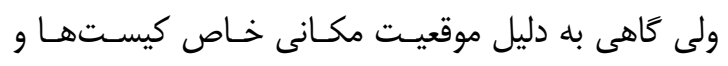

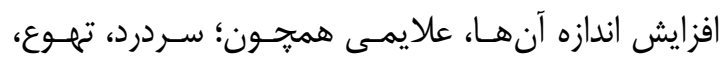

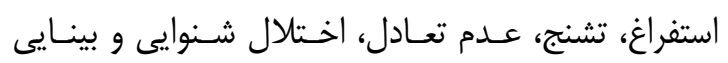

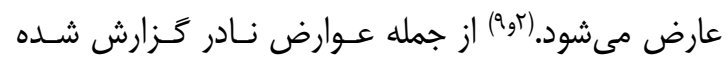

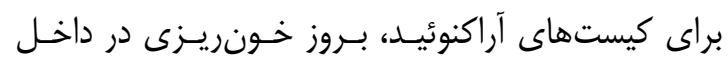

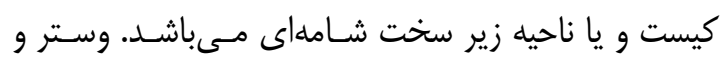

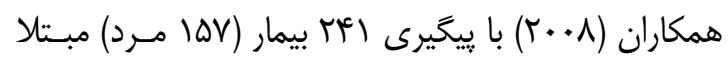

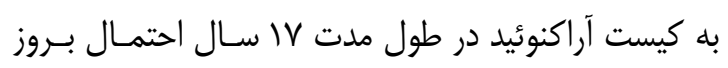

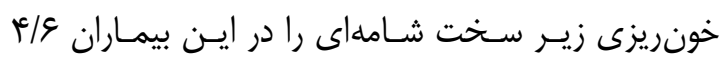

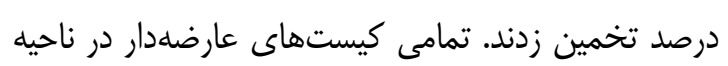

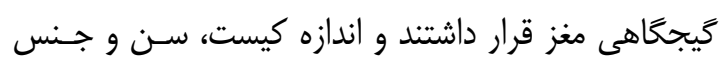
بيماران در بروز خونريزى بى تـأثير بودنــــ خطـر سـاليانه بروز خونريزى در كيستهاى ناحيه كيجخـاهى نيـز / /.

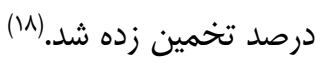
اولين مورد بروز خونريزى در كيستهــاى آراكنوئيـد

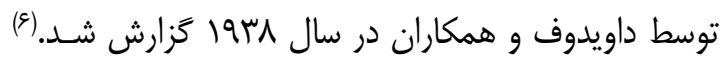

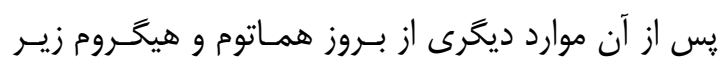

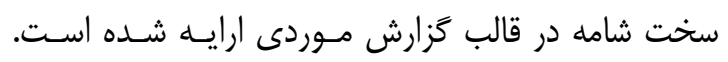

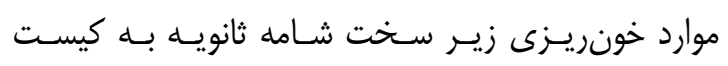

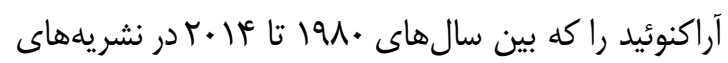

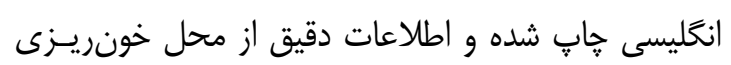
ارايه كردهاند، بهطور خلاصه مرور شدهاند (جدول شماره ()).

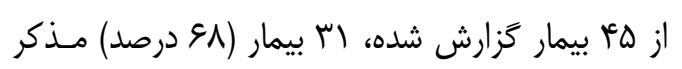

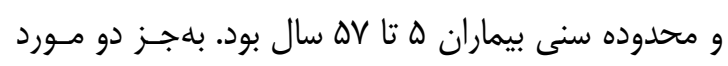

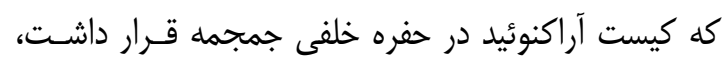

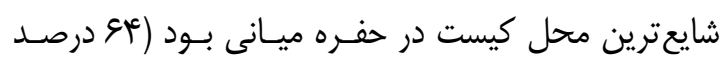

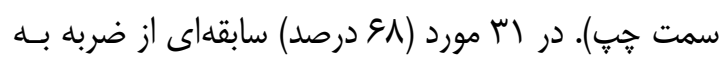

تهوع يا استفراغ بود. قبل از شروع سردرد، علايمى دال بر

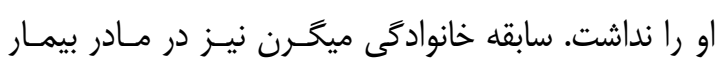

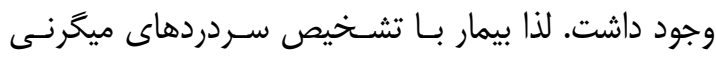

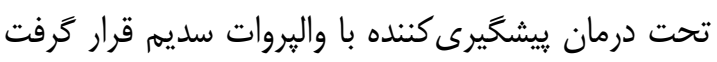

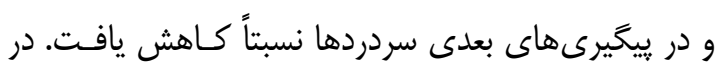

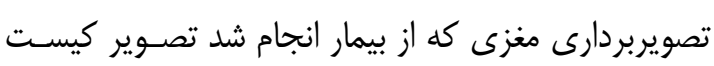

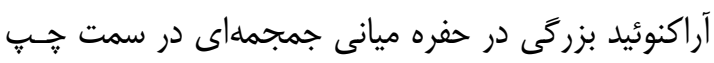

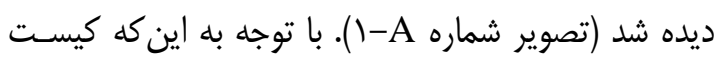

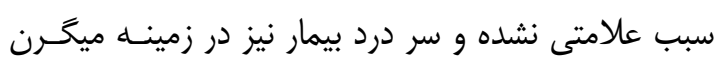
قابل توجيه بود، اقدام خاصى براى درمان كيست صـورت

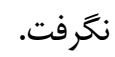

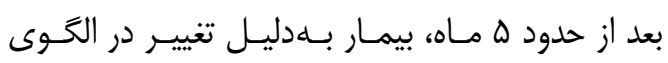

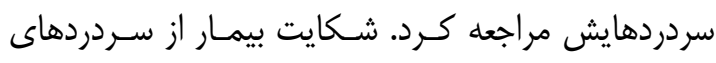

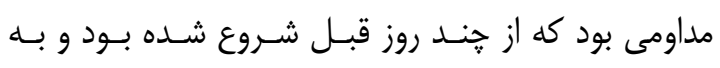

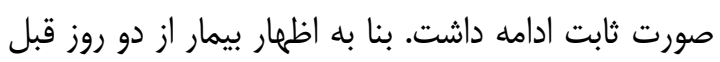
احساس ضعفى در دست راست هم ايجاد شده بـود. اخيـراً

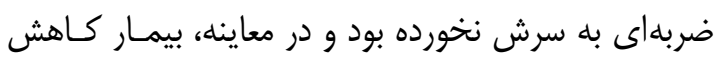
مختصر قدرت عضلانى در اندامهاى سمت راسـت همــراه

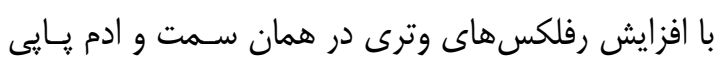

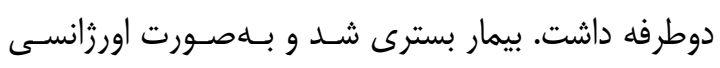

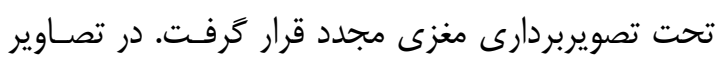
جديد علاوه بر كيست آراكنوئيد قبلى، تصوير هماتوم زيــر

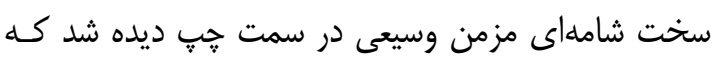

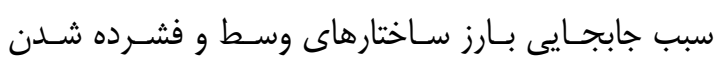

بطن هاى طرفى ترديده بود (شكل شماره ا (B-C) (B).

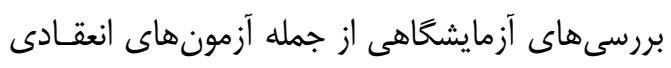

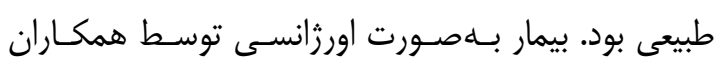

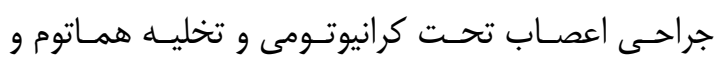

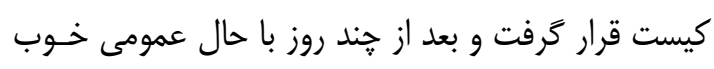

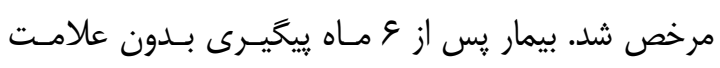

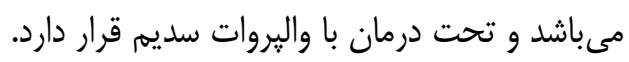

\section{بحث و نتيجه}

بيمار معرفى شده نشان داد كه حتى در غياب عوامـل 
سر (حتى از نوع خفيف)، مطرحكننده نقش ضربه بــه سـر

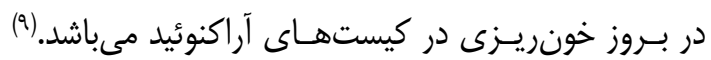

سر وجود داشت كه در بيماران گزارش شده توسط مـورى

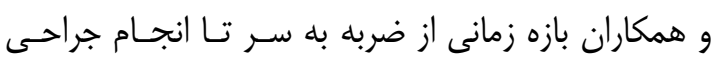

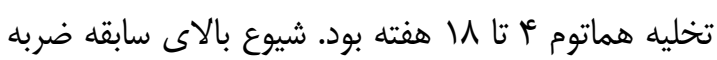
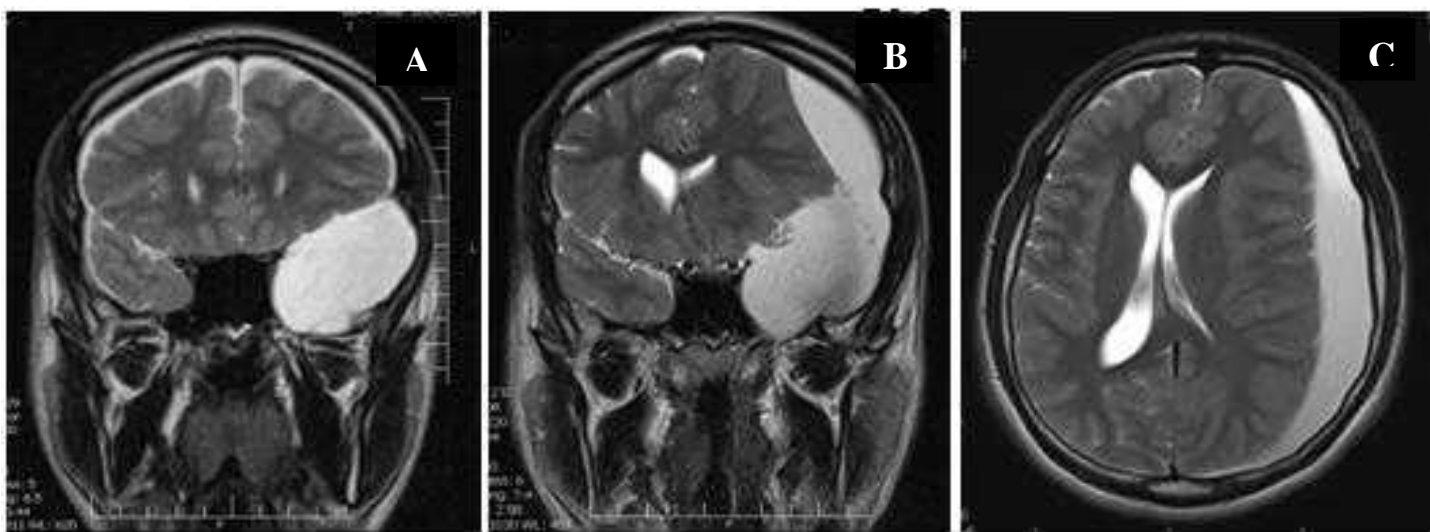

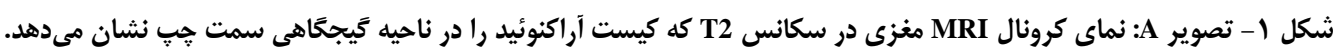

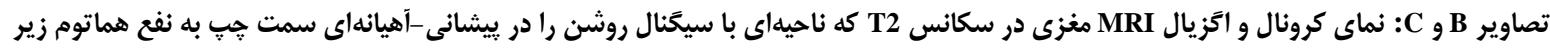

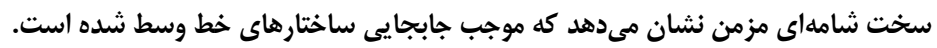

جدول ا - موارد تَزارش خونريزى زير سخت شامه در زمينه كيست آراكنوئيد در مقالههاى جابٍ شده در نشريههاى انخليسى

\begin{tabular}{|c|c|c|c|c|c|}
\hline \multicolumn{2}{|c|}{ سمت دركير در فضاى مغزى ميانى } & \multirow{2}{*}{ سابقه ضربه به سر } & \multirow{2}{*}{ محدوده سنى (سال) } & \multirow{2}{*}{ تعداد بيماران } & \multirow{2}{*}{ (سال انتشار) } \\
\hline خونريزى سابدورال & كيست آراكنوئيد & & & & \\
\hline س مورد جֶٍ، ا مورد راست & س مورد جֶי، ا مورد راست & · & 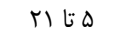 & $(r) r$ & 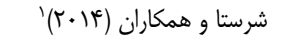 \\
\hline ح & جֶ & 1 & 9 & $(\cdot) 1$ & 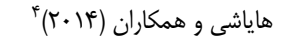 \\
\hline r مورد حֶי، ا مورد راست & r مورد حֶ)، ا مورد راست & r & 酒 & $(r) r$ & ليو و همكاران (F. (T)ه \\
\hline קט & $\because$ & 1 & 8 & (1) 1 & كاهيلوَّولارى و همكاران (rا. (r)" \\
\hline r مورد هֶ & r مورد جֶ & · & هV & (1) $r$ & كاندوز و همكاران (•l一 r r) \\
\hline ७ & $\stackrel{\nabla}{\nabla}$ & 1 & 10 & (1) 1 & 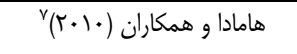 \\
\hline r مورد حت & ا مورد جֶٍ، ا مورد راست & r & سזr إ) & $(r) r$ & 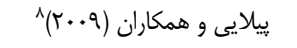 \\
\hline 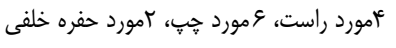 & أمورد راست، كمورد حֶ)، بمورد حفره خلفى & 1. & 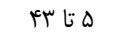 & (9) Ir & مورى و همكاران (Y..r) \\
\hline r مورد هֶ & r مورد هֶ & r & 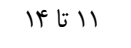 & $(r) r$ & كاوانيشى و همكاران (1999)'1 \\
\hline r مورد حֶי، זمورد راست & r مورد حֶי، זمورد راست & f & ع تاه & $(\Delta) \Delta$ & آلبوكوئر و و همكاران (199V)" \\
\hline 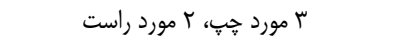 & r مورد حֶי، مورد راست & r & | & $\left(v^{c}\right) \Delta$ & سنر (1997) \\
\hline "זمورد راست، "َمورد جֶٍ، امورد دوطرفه & 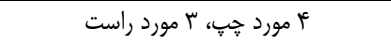 & f & AV & $(\Delta) V$ & يبج و همكاران (19AV) \\
\hline
\end{tabular}


بروز خونريزى در كيستهاى آراكنوئيد است، مرورى بـر

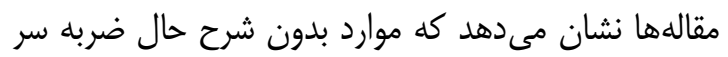

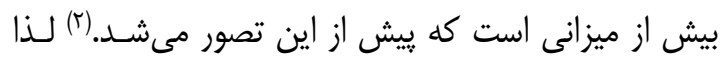

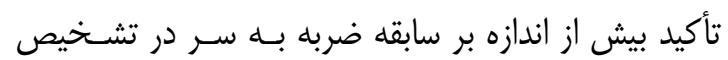

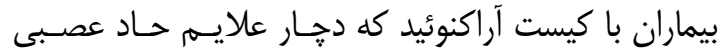

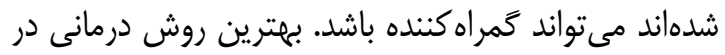
خونريزىهاى زير سخت شامهاى مزمن در زمينه كيست

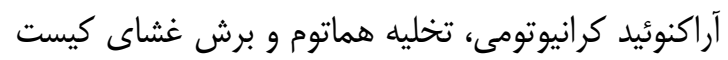

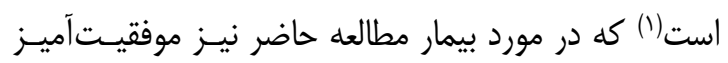

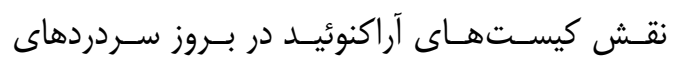
ميكرنى در مطالعههاى مختلفى ارزيـابى شـده كـهـ نتـايج

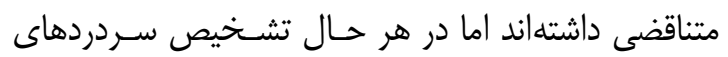
مشخص ميخرنى در زمينه كيست بدون عارضه آراكنوئيـد

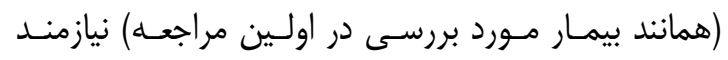

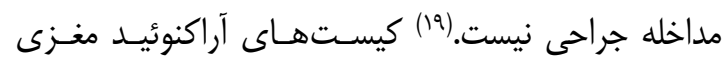

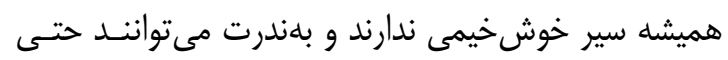

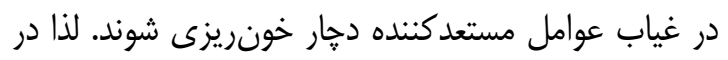

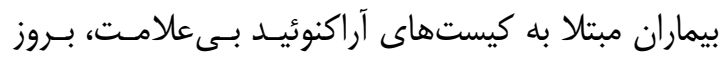
هر گونه علامت حاد يا تحت حـاد عصـبى از جملـه تغييـر

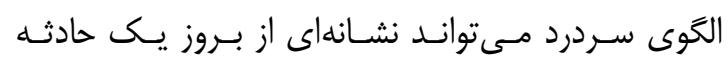

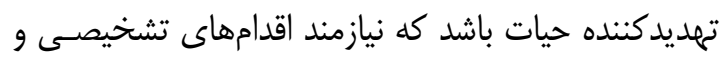
درمانى فورى است.

\section{:مراجع:}

1. Shrestha R, You C. Spontaneous chronic subdural hematoma associated with arachnoid cyst in children and young adults. Asian $\mathrm{J}$ Neurosurg 2014; 9(3): 168-72. doi: 10.4103/ 1793-5482.142739.

2. Gunduz B, Yassa MI, Ofluoglu E, Ekinci B, Erdogan U, Asilturk M, et al. Two cases of arachnoid cyst complicated by spontaneous intracystic hemorrhage. Neurol India 2010; 58(2): 312-5. doi: 10.4103/0028-3886.63795.

3. Westermaier T, Schweitzer T, Ernestus RI.

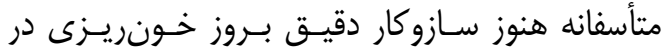

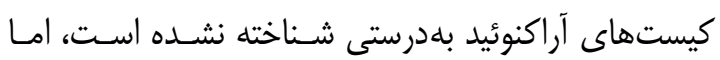

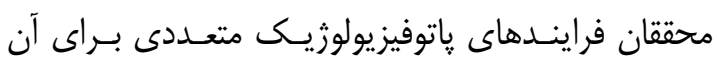

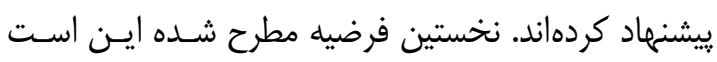

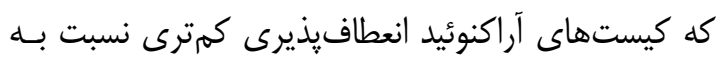

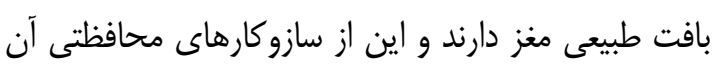

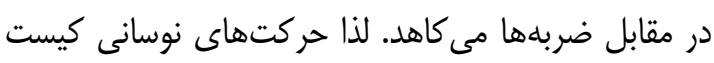

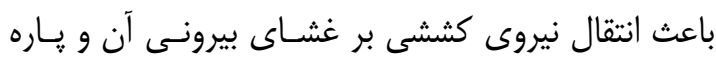

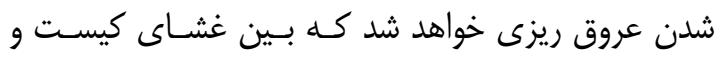

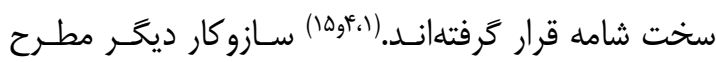

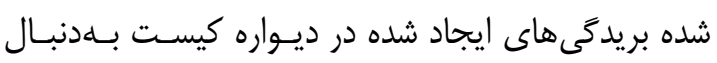

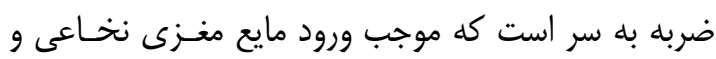

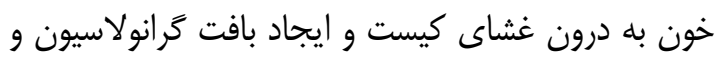

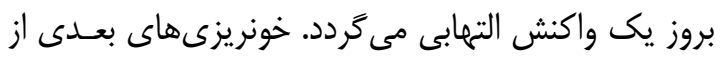

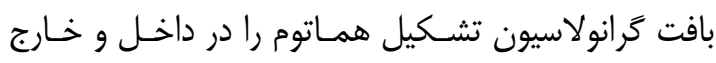

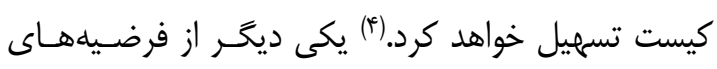

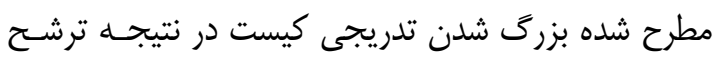

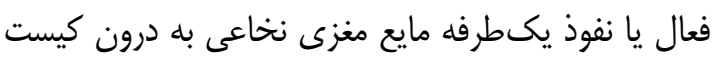

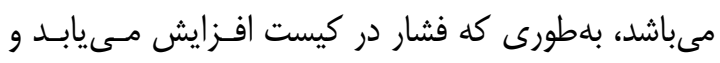

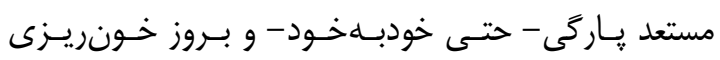

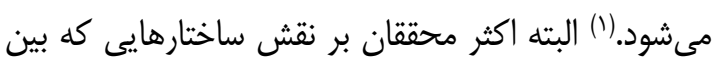

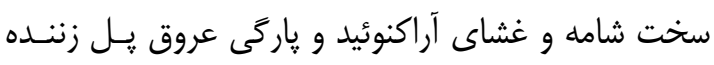

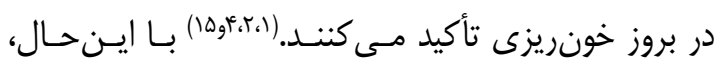

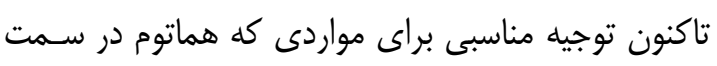
مقابل كيست تشكيل شده، ارايه نشده است. (موهام

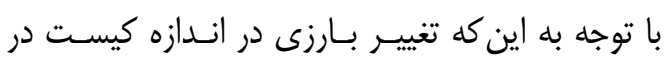

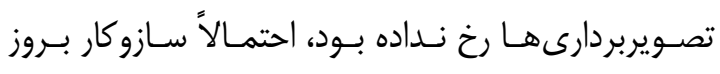

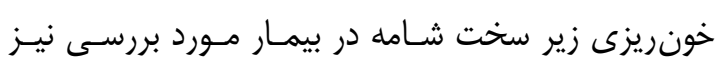

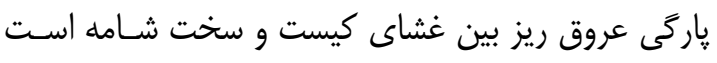

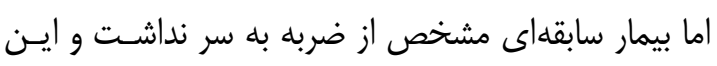

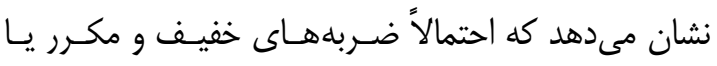

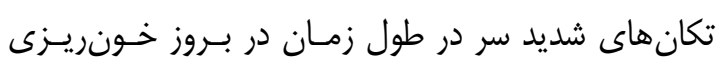

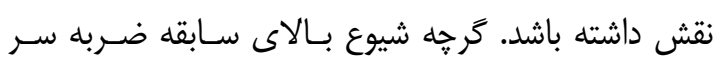

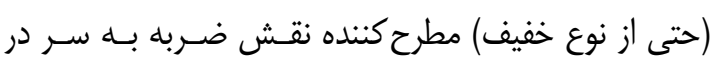


Arachnoid cysts. Adv Exp Med Biol 2012; 724: 37-50. doi: 10.1007/978-1-4614-06532_3.

4. Hayashi Y, Kita D, Kinoshita M, Hamada J. Hematoma within the outer membrane of the arachnoid cyst located in the middle fossa: a mechanism of development of chronic subdural hematoma associated with arachnoid cysts. Open J Modern Neurosurgery 2014; 4(2): 97-103. doi: 10. 4236/ojmn.2014.42018.

5. Liu Z, Xu P, Li Q, Liu H, Chen N, Xu J. Arachnoid cysts with subdural hematoma or intracystic hemorrhage in children. Pediatr Emerg Care 2014; 30(5): 345-51. doi: 10. 1097/PEC.0000000000000128.

6. Kahiloğullari G, Eroğlu U, Bozkurt M, Ünlü A. Arachnoid cyst with spontaneous subdural hematoma and intracystic hemorrhage in a child. Ankara Üniversitesi Tıp Fakültesi Mecmuası 2013, 66(2): 91-3. doi: 10.1501/Tipfak_000000848.

7. Hamada H, Hayashi N, Umemura K, Kurosaki K, Endo S. Middle cranial fossa arachnoid cyst presenting with subdural effusion and endoscopic detection of tear of the cyst--case report. Neurol Med Chir (Tokyo) 2010; 50(6): 512-4.

8. Pillai $\mathrm{P}$, Menon SK, Manjooran RP, Kariyattil R, Pillai AB, Panikar D. Temporal fossa arachnoid cyst presenting with bilateral subdural hematoma following trauma: two case reports. J Med Case Rep 2009; 3: 53. doi: 10.1186/1752-1947-3-53.

9. Mori K, Yamamoto T, Horinaka N, Maeda M. Arachnoid cyst is a risk factor for chronic subdural hematoma in juveniles: twelve cases of chronic subdural hematoma associated with arachnoid cyst. J Neurotrauma 2002; 19(9): 1017-27. doi: 10.1089/ 089771502760341938.
10. Kawanishi A, Nakayama M, Kadota K. Heading injury precipitating subdural hematoma associated with arachnoid cysts-two case reports. Neurol Med Chir (Tokyo) 1999; 39(3): 231-3. doi: 10.2176/nmc.39.231. 11. Albuquerque FC, Giannotta SL. Arachnoid cyst rupture producing subdural hygroma and intracranial hypertension: case reports. Neurosurgery 1997; 41(4): 951-5.

12. Parsch CS, Krauss J, Hofmann E, Meixensberger J, Roosen K. Arachnoid cysts associated with subdural hematomas and hygromas: analysis of 16 cases, long-term follow-up, and review of the literature. Neurosurgery 1997; 40(3): 483-90.

13. Sener RN. Arachnoid cysts associated with post-traumatic and spontaneous rupture into the subdural space. Comput Med Imaging Graph 1997; 21(6): 341-4. doi: 10. 1016/S0895-6111(97)00036-0.

14. Page AC, Mohan D, Paxton RM. Arachnoid cysts of the middle fossa predispose to subdural haematoma formation fact or fiction? Acta Neurochir Suppl (Wien) 1988; 42: 210-5.

15. Page A, Paxton RM, Mohan D. A reappraisal of the relationship between arachnoid cysts of the middle fossa and chronic subdural haematoma. J Neurol Neurosurg Psychiatry 1987; 50(8): 1001-7.

16. Galassi E, Tognetti F, Pozzati E, Frank F. Extradural hematoma complicating middle fossa arachnoid cyst. Childs Nerv Syst 1986; 2(6): 306-8.

17. Auer LM, Gallhofer B, Ladurner G, Sager WD, Heppner F, Lechner H. Diagnosis and treatment of middle fossa arachnoid cysts and subdural hematomas. J Neurosurg 1981; 54(3): 366-9.

18. Wester K, Helland CA. How often do chronic extra cerebral haematomas occur in 
patients with intracranial arachnoid cysts? J Neurol Neurosurg Psychiatry 2008; 79(1): 72-5. doi: 10.1136/jnnp.2007.117358.
19. Cherian J, Viswanathan A, Evans RW. Headache and arachnoid cysts. Headache 2014; 54(7): 1224-8. doi: 10.1111/head. 12415. 